\title{
Quantitative Cell Numbers and Density of Mesangial Volume in a Rat Model with Induced Hyperglycemic and Treated with Mononuclear Derived CD133 Positive Cells
}

\author{
Durdi Qujeq $^{1,2^{*}}$, Fariba Salmani ${ }^{2}$, Farideh Feizi ${ }^{3}$ \\ ${ }^{1}$ Cellular and Molecular Biology Research Center (CMBRC), Babol University of Medical Sciences, Babol, Iran. \\ ${ }^{2}$ Department of Biochemistry and Biophysics, Faculty of Medicine, Babol University of Medical Sciences, Babol, Iran. \\ ${ }^{3}$ Department of Anatomical Sciences, Faculty of Medicine, Babol University of Medical Sciences, Babol, Iran.
}

Received: 14 Jan 2014

Revised : 24 Feb 2014

Accepted: 8 Mar 2014

Corresponding Authors: Durdi Qujeq

Head of Department of Biochemistry and Biophysics .Cellular and Molecular Biology Research Center (CMBRC), Babol University of Medical Sciences, Ganjafrooze Avenue, Babol, Iran.

Phone:+98-1112229591-5

E-mail: dqujeq@hotmail.com

\begin{abstract}
Background: There is evidence that mesangial cell structural changes contribute to the pathogenesis of diabetic nephropathy. To gain better insight into the mechanisms responsible for this issue, present study focused on effect of cord blood mononuclear cells (MNCs) derived CD133 positive cells on mesangial cell structure and function.

Materials and Methods: The animals were randomly divided into four groups (each with six rats) and were kept in separate cages as follows: Group I: control group, received only $8.2 \mathrm{mmol} / \mathrm{L}$ sodium citrate buffer $(\mathrm{pH} 5.4)$. Group II: received only CD133 positive cells. Group III: received alloxan $(65 \mathrm{mg} / \mathrm{kg})$ only. Group IV: received alloxan, followed by administration of CD133 positive cells, 1 week later. Rats were studied for 16 weeks. Cord blood mononuclear cells (MNCs) were isolated by a conventional centrifuge method through a Ficolldensity gradient, CD133 positive isolation was performed by means of magnetic cell separation (MACS) columns according to the manufacturer's procedure. CD133 positive stem cells analyzed using flow cytometry. The CD133positive cells were centrifuged, re-suspended with $\mathrm{PBS}$, and transplanted to the rats through the tail. At the end of the experiments, blood was collected, and then blood glucose, creatinine, glycated hemoglobin and insulin concentrations were measured by using kits.

All of the animals were killed and the kidneys were removed. Tissues were processed for light microscopy. Glomerular features were evaluated quantitatively using Cavalieri and disectory methods and compared with sham and control groups.

Results: Our results indicated that treated hyperglycemic rats showed an increase in mesangial volume compared to untreated group. Concerning the mechanisms of these findings both glycemic control and CD133 positive cells regenerative potential are major's factors to change mesangial structure and function.

Conclusion: The present study clearly documents the potential of CD133 positive cells on the renal mesangial cells.
\end{abstract}

Keywords: Hyperglycemic; Mesangial ; CD133positive cells

Please cite this article as: Qujeq D, Salmani F, Feizi F. Quantitative Cell Numbers and Density of Mesangial Volume in a Rat Model with Induced Hyperglycemic and Treated with Mononuclear Derived CD133 Positive Cells. Res Mol Med. $2014 ; 2$ (2): $22-27$

\section{Introduction}

There are evidence that mesangial structural changes contribute to the pathogenesis of diabetic nephropathy (1). It is important to note that the structural lesionsthat characterize diabetic nephropathy include the expansion of mesangial volume (2). On this line, there are some reports in the literature showing that the dysfunction of mesangial cells is one of the key factors causing glomerular injury in diabetic 
nephropathy. It is important to note that when exposed to the diabetic metabolicmilieu,mesangial cells display growth abnormalities (3). It has also been shown that diabetic nephropathy is associated with the accumulation of extracellular matrix proteins in the glomerulus.Itis speculated that the state of hyperglycemia is the primary etiologic factor in the metabolic abnormalities of diabetes.Preliminary studies revealed that prolonged exposure to high glucose is an important contributor to the development of diabetic nephropathy in diabetes (4-6). The purpose of the present study was to examine the effect of CD133 positive cells on the mesangial cells structure and function.

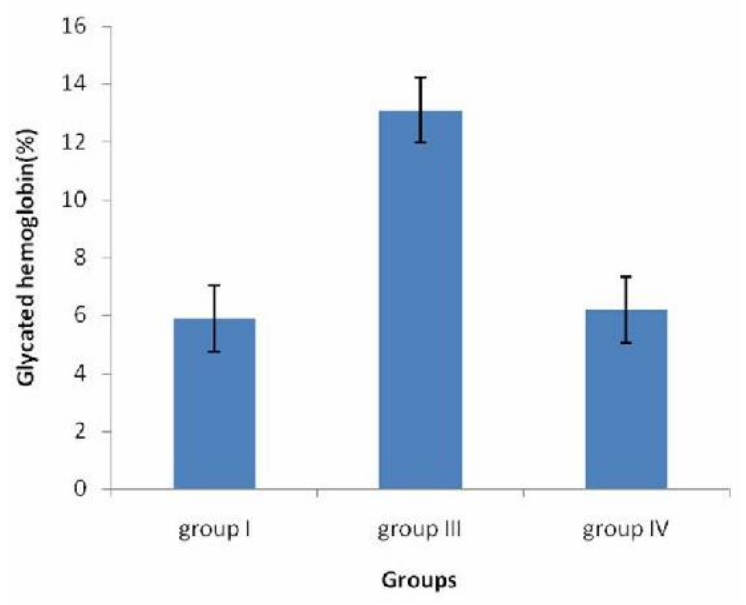

Figure 1. Glycated hemoglobin level in control group (group I), hyperglycemic group (group III) and CD133 positive treated rats (group IV). Values presented are mean \pm SD of 6 rats for each group, $P<0.05$.

\section{Material and Methods \\ Animals}

Male rats were purchased from Babol University of Medical animal center, housed in an animal room under controlled temperature $\left(20-25^{\circ} \mathrm{C}\right)$, and a 12-h light/dark cycle with free access to water and food. The animals were randomly divided into four groups (each with six rats) and were kept in separate cages as follows: group I; control group, received only citrate buffer, group II received only CD 133 positive cells; group III: received alloxan only; group IV: received alloxan, followed by administration of CD133 positive cells 1 week later. All animal experiments were performed according to local laws and in accordance with the University of Babol for Laboratory Animal Research Guide for Care and Use of Laboratory Animals (No: PJ30-5224, 90/9/28).

\section{Experimental design}

Control rats were injected with an equivalent volume of sodium citrate buffer alone (group I). CD133 positive cells were infused through the tail vein (group II). Experimental hyperglycemic rats (groups III and IV)was induced by injecting $65 \mathrm{mg} / \mathrm{kg}$ alloxan (A 7413-25 g, Aldrich, C4H2N2O4, H2O) was dissolved in $8.2 \mathrm{mmol} / \mathrm{L}$ sodium citrate buffer $(\mathrm{pH}$ 5.4) through the intraperitoneal within $10 \mathrm{~min}$ of preparation. Hyperglycemic rats were then randomized to receive no cell treatment (group III), $(n=6)$, or $\left(3-4 \times 10^{6}\right)$ of CD133 positive cells (group IV), cell counted by using cell counter (Sysmex x1000i). CD133 positive cells were infused through the tail vein 7 days after the alloxan injection when blood glucose was more than $250 \mathrm{mg} / \mathrm{dl}$. The effective dosage of CD133 positive cells was determined through preliminary experiments. After 16 weeks of hyperglycemic, the rats were sacrificed, and the blood was collected for determinations of biochemical parameters and kidneys were then excised for morphometric analysis.

\section{Isolation of Cord Blood MNCs}

Isolation cord blood MNCs was performed as described previously (7). Human UCB cells were obtained from full-term normal deliveries. Blood samples $(n=6)$ from the umbilical cord were obtained from the Ayatollah Rouhhani Hospital of Babol University of Medical Sciences, Babol, Iran. Informed consent was obtained from the mothers whose umbilical cord blood was collected. The approval of the Ethics Committee of Babol University was obtained (No: 91919-1671). Sample codes were (No: 181237, 173688, 181621, 181219, 181206 and 180866). Each cord blood sample was collected into a $50 \mathrm{ml}$ sterile polypropylene test tube containing 5 $\mathrm{ml}$ of citrate phosphate dextrose (Sigma, USA) as an anticoagulant.

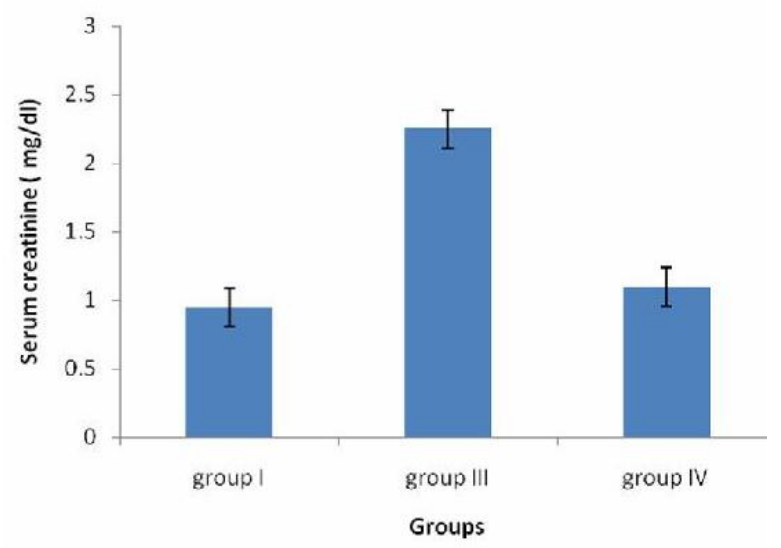

Figure 2. Serum creatinine content in control group (group I), hyperglycemic group (group III) and CD133 positive treated rats (group IV). Values presented are mean $\pm \mathrm{SD}$ of 6 rats for each group, $\mathrm{P}<0.05$. 
The mean volume of cord blood varied from 36 to 49 mL. Immediately after collection of UCB samples, approximately $10 \mathrm{~mL}$ of collected cord blood was mixed with the same volume of phosphate buffered saline (PBS), (Gibbon, 10010-015).

Units were placed in a $10 \mathrm{ml}$ disposable centrifuge tube. An aliquot of $10 \mathrm{ml}$ of this cell suspension was carefully layered onto the top of $10 \mathrm{ml}$ of FicollpaqueTM premium (Sweden 17-5442-02) and subjected to density-gradient centrifugation (Centrifuge, Behdad; Iran) at $1700 \mathrm{rpm}$ for $35 \mathrm{~min}$. After 35 mines of centrifugation in a swinging bucket rotor, the inter mediate layer was collected. Upon isolation, the cells of the mononuclear fraction were separated and counted (Hematology cell counter, Lc10, Austria micros).

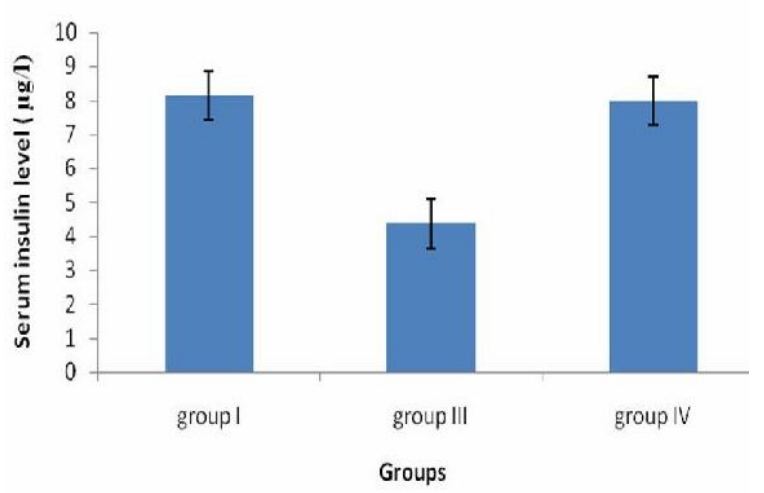

Figure 3. Serum insulin level in control group (group I), hyperglycemic group (group III) and CD133 positive treated rats (group IV). Values presented are mean $\pm \mathrm{SD}$ of 6 rats for each group, $P<0.05$.

\section{Isolation of CD133 positive cells}

Isolation of CD133 positive cells was carried out as described previously (8-9) CD133 positive isolation was performed by means of CD133-conjugated super paramagnetic microbeads and magnetic cell separation (MACS) columns (Octo MACS Acryl tube Rack, 130-090-448, 5100719002, Miltenyi Biotech, Gmb H, MS Column Adapter, 130-090-543, 5100728182; MACS separation columns 130-042-201; sterile packed, $5 \mathrm{ml}$-Bottom tube $5 \mathrm{ml}$ tubes for MS columns, sterile packed, 130-091-598) and antibodies recognizing the $\mathrm{CD} 133+$ epitope according to the manufacturers procedure (CD133 Micro Bead Kit, 130-050). MNC cells were incubated with CD133 antibody conjugated to micro beads for $30 \mathrm{~min}$ at 5 ${ }^{\circ} \mathrm{C}$. After incubation, cells were washed in phosphatebuffered saline (PBS) supplemented with $2 \mathrm{mmol} / \mathrm{l}$ EDTA and $0.5 \%$ fetal calf serum (FCS), (Promo Cell R). Cells were passed through a Mini-MACS column retained in a magnetic field, and the column was washed with PBS to remove unbound cells. CD133 positive cells were recovered by releasing the magnetic field and flushing cells from the column. After separation, cell populations were counted on an automatic cell counter (Sysmex-1000i). For characterization of CD133 positive stem cells in bloods was determined using Flow cytometry (Control Gama 1 fluorescein isothioocyanate conjugated (FITC) + gamal phycoerythin conjugated (PE) + CD34 FITC, ton Dickinson TriTEST; PAS, Germany). Seven days after alloxan injection, rats were randomly divided into a control group (group II) and CD133 positive cell-treated rats (group III). The CD133 positive cells were centrifuged, re-suspended with PBS, and transplanted to the rats (group III) through the tail vein. After 4-16 weeks of hyperglycemia, blood was collected in test tube. At 16 weeks after treatment, the rats were sacrificed.

\section{Morphometric analysis}

Approximately 8-10 slices were obtained from each kidney. The slices were arranged in a number of sequences on meshed tissue processing baskets and then they were processed and embedded in paraffin. The blocks were systematically sectioned at 5 micrometer, and every sixth section in order, with the first chosen randomly in the interval 1-7, was on glass slides and stained with Periodic Acid Schiff (PAS). Every first and seventh section was selected for stereological analysis, which involved the use of microscopes (model BH2, Olympus Optical). To estimate the volume of cortex, medulla and whole kidney every first section was viewed on a loop microscope (Motic) at a magnification of 20X. Then the image was projected on a computer monitor.

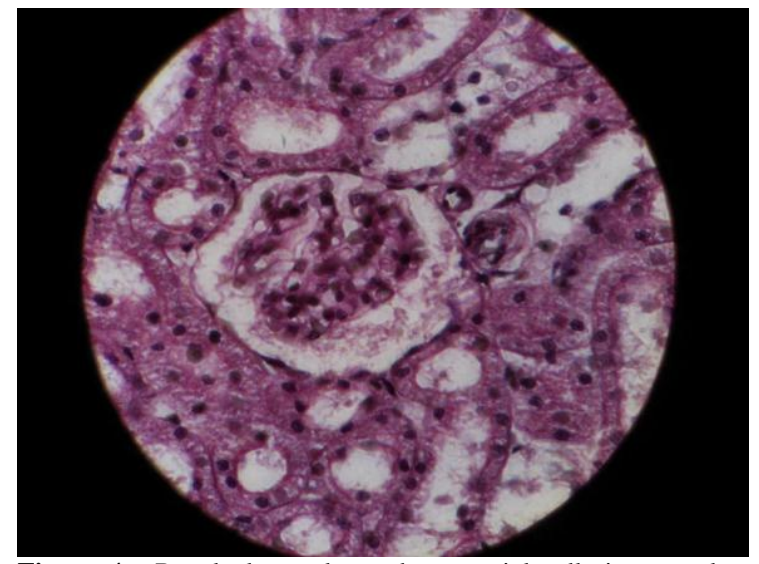

Figure 4a. Renal glomerular and mesangial cells in control rats (group I).

A fine grid of points $(6 \mathrm{~mm})$ was superimposed over the visual field of the sampled sections. Point counting using Cavalieri principle was used to estimate the volume of cortex, medulla and whole kidney. The volume was estimated from the following equation. 


$$
V(K I D)=\frac{\sum \text { pi.a/p.t }}{M^{r}}
$$

$\mathrm{V}$ is the volume of kidney, $\sum \mathrm{P}$ is the sum of all points counted in sections, $a / p$ is the area associated with each point, $\mathrm{t}$ is the distance between two consecutive sections that we have counted points in, $\mathrm{M}$ is the linear magnification of projector (10-13).

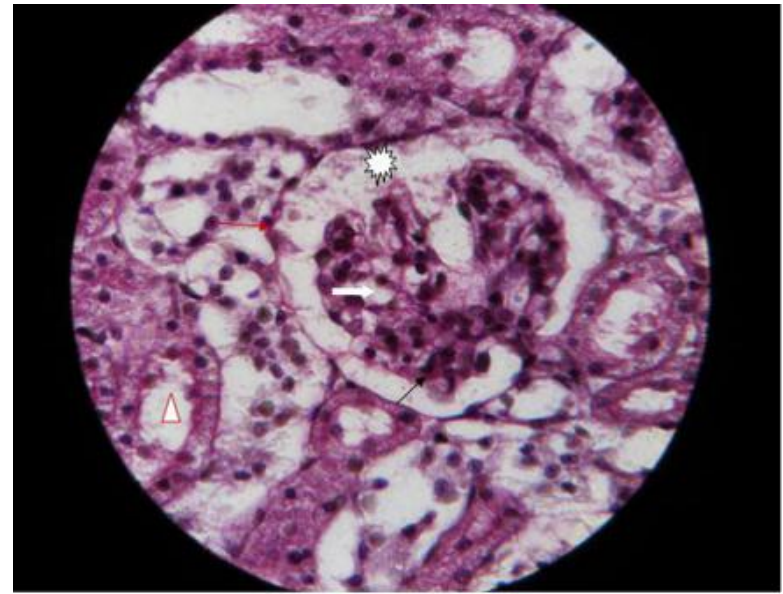

Figure 4b. Renal Glomerular and tubular in hyperglycemic rats that treated with CD133+ (group IV). Red arrow, renal corpuscle; Star, bowman capsular area; black arrow, mesangial cells; whit arrow, blood capillary; red triangle; proximal cylinder.

\section{Assay for Biochemical parameters}

The measurements of biochemical parameters including serum creatinine, glycated hemoglobin, glucose and insulin levels were performed at the time of final assessment with commercially available standard methods.

Brifly, glucose was measured by glucose oxidase method kit (Pars Azmoon, Tehran, Iran). Serum creatinine was measured based on the Jaffe reaction by kit (Pars Azmoon, Tehran, Iran). Glycated hemoglobin levels was measured by using Elisa kit (Bioassay technology laboratory, Elisa kit).

The insulin level was measured following Elisa assay by the insulin kit specific for rats made by Mercodia Co., Sweden with EIA plate reader with $450 \mathrm{~nm}$ filter (Statfax 2100, USA). The biochemical parameters level were measured before the animals received the alloxan and CD133 positive cells and at 1, 4, 8, 12 and 16 weeks after treatment. The rats were followed for a mean of 16 weeks.

\section{Statistical analysis}

The data was assessed for statistical significance using student $\mathrm{t}$-test statistics. Results were expressed as mean \pm standard error. The paired sample t-test was performed by a computer program (SPSS for windows, version 16.0). A p-value $<0.05$ was used as the criterion for a statistically significant difference.

\section{Results}

There was no immunological reaction in groups I and II. Hyperglycemic was confirmed by glycated hemoglobin and glucose levels estimation in groups III and IV. Findings here in showed that hyperglycemic animals demonstrated elevated glycated hemoglobin level $(13.1 \pm 1.2 \%$ vs. $6.2 \pm 0.8$ $\%, \mathrm{P}<0.05$ ) (Figure1). Also, hyperglycemic rats showed increased blood creatinine $(2.25 \pm 0.34 \mathrm{mg} / \mathrm{dl})$ compare to treated with $\mathrm{CD} 133$ positive cells group $(1.1 \pm 0.36 \mathrm{mg} / \mathrm{dl}, \mathrm{P}<0.05)$, as shown in figure 2 . Figure 3 shows the blood insulin levels in the untreated and CD133 positive-treated groups after 16 weeks. As demonstrated in figure 3 after injection of alloxan, the blood insulin level after 7 days was $4.383 \pm 1.01 \mu \mathrm{g} / \mathrm{l}$ in rats. But, insulin level in CD133 positive transplanted rats began to increase at 16 weeks after transplantation, kept above $7.98 \pm 1.12$ $\mu \mathrm{g} / \mathrm{l}$. Renal glomerular and mesangial cells in control rats was shown ( Figure 4a). Renal Glomerular and tubular in hyperglycemic rats that treated with CD133+ (group IV) was shown (Fig 4b) .Also, renal glomerular and cylinder in hyperglycemic rats (Group III) was shown (Figure 4c). Morphometric measurements revealed differences in the mean density mesangial volume( Figure 5) between treated with CD133 positive cells $\left(0.83 \pm 0.03 \mathrm{~mm}^{3}\right)$ compare to untreated hyperglycemic rats( $0.73 \pm 0.06$ $\mathrm{mm}^{3}$ ), no significant $\mathrm{P} \geq 0.05$. On the other hand, expansion of the mesangial matrix and mesangial area was seen in CD133 positive cells treated rats.

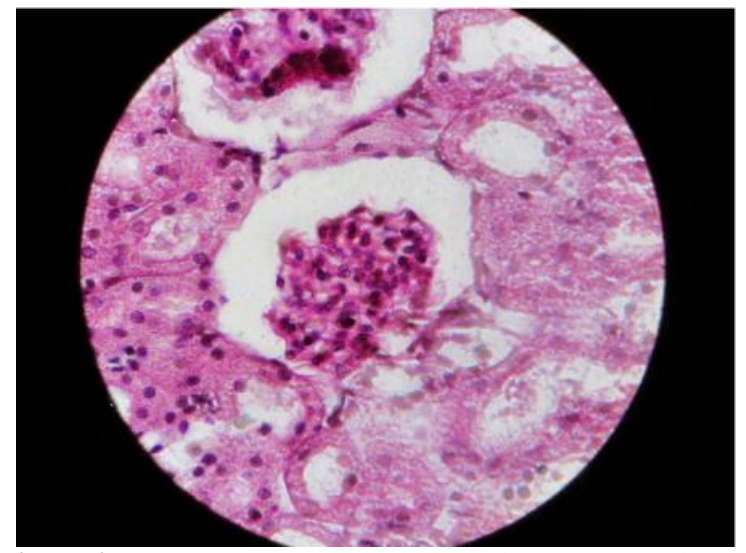

Figure 4c. Renal glomerular and cylinder in hyperglycemic rats (Group III). Enlarged bowman capsular area and closed blood capillary.

\section{Discussion}

Several lines of evidence indicate that the increase of blood glucose may be causally involved in development of diabetic nephropathy. However, the 
potential role of hyperglycemia in hypertrophy of renal cells has been poorly studied. Prevention early hyperglycemic is major health care issue. It is impossible for us to understand the diabetes without knowing the role of hyperglycemia. In this respect as reported by many investigators despite the recent advances made in the hyperglycemia there is still an enormous amount of research that needs to be conducted in this field.

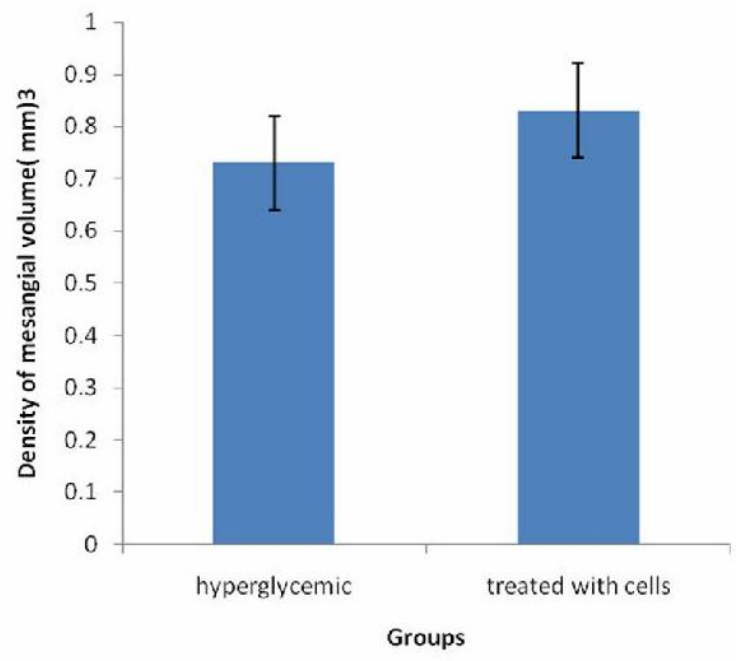

Figure 5. Mean Density of mesangium volume in hyperglycemic (group III) and CD133 positive -treated rats (group IV). Values presented are mean $\pm \mathrm{SD}$ of 6 rats for each group, $P<0.05$.

In this respect recent years has provided new data supporting the use of stem cell for the treatment of hyperglycemic complications.

However, among the issues raised, the possible contribution of these cells to treatment of hyperglycemic status require further investigations. Therefore, a greater understanding of stem cell character is needed to establish the safety of their use as a novel and efficient therapeutic agents in the treatment of complications of hyperglycemia.

Based on the present results we suggested that the hyperglycemia could be implicated in mesangial cell structure and function. Therefore changes of mesangial cells may be cause kidney lesions. Our results demonstrated that in treated with $\mathrm{CD} 133$ positive cells, mild mesangial expansion accompanied was observed at 16 weeks of age. But, such mesangial changes were absent in alloxanhyperglycemic rats.

These results are in accordance with findings of other studies (14-15) that they demonstrated that hyperglycemia cause inhibit cell proliferation, increase apoptosis and causing changes in the extracellular matrix. In this respect, increased intracellular glucose may changes in the mesangial cell structure and function. Mesangial structural changes contribute to the pathogenesis of hyperglycemic nephropathy.

The increase of creteanine and histological changes in 16-weeks-old alloxan -hyperglycemic rats in the present study were expected. The increase of creatinine as renal function fails has been thoroughly documented for hyperglycemic nephropathy. The reciprocal of serum creatinine concentration has also been used as a guide in flowing and documenting the rate of loss of renal function. Based on present findings, we hypotheses that mesangial structural changes, increase serum glucose and also increase creatinine contribute to the pathogenesis of hyperglycemic nephropathy. These findings suggests the possibility that decreased cretinine and glucose, in contrast increase insulin level were caused by the effect of CD133positive cells. We postulated that the ability of CD133 positive cells to treat or reduce hyperglycemic neuropathy may be because of: I) the modulate the damage effect of hyperglycemia on the kidney cells. II) The decrease in blood toxicity. III) The homing of CD133 positive cells to renal cells. IV) The ability of these cells to repair the renal tissue V) Associate with improving in mesangial morphology. VI) Play role in regulation of biochemical metabolism. Concerning the mechanisms of these findings both glycemic control and CD133 positive cellsregenerative potential are major's factors to change mesangial structure.

The main limitation of the present study is that we cannot describe the mechanism of how CD133 positive cells influence on kidney cells. Another limitation is the fact that we cannot completely rule out the influence of CD133 positive cells on the mesangial.

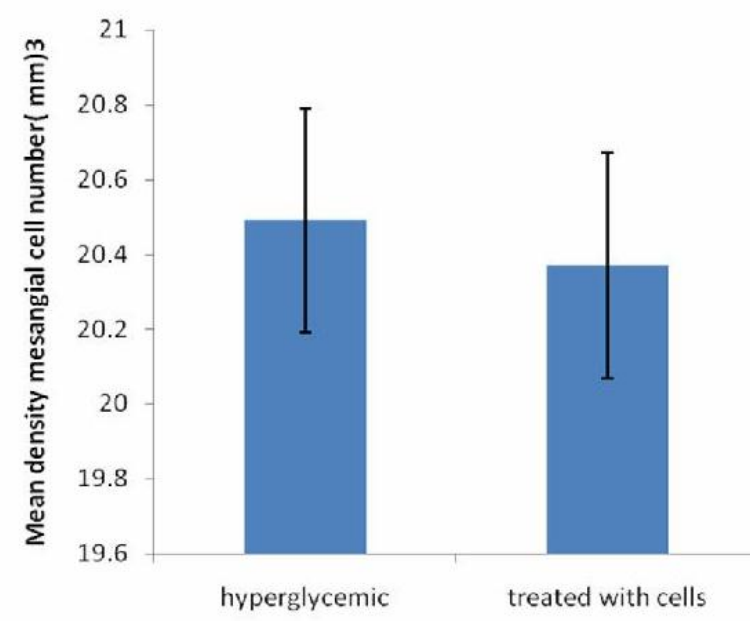

Figure 6. Mean density mesangial cell number in hyperglycemic (group II) and CD133 positive-treated rats (group III).Values presented are mean $\pm \mathrm{SD}$ of 6 rats for each group, $P<0.05$. 


\section{Conclusion}

Observation of the present study taken together with previous studies raise a new hypothesis on the potential involvement of hyperglycemic in development of mesangial cells hyperplasia and increase contribute to glomerular enlargement .Also, added new mechanisms effect of CD133 positive cells on renal cells. In addition, the results of our study demonstrated that the beneficial effects of CD133 positive cells may be due to its glycemic control property and regenerative potential. In this respect, glycemic control may be inhibit both the functional and structural lesions of mesangial cells. However, extensive experimental studies are required in large numbers of samples to establish the efficacy of CD133 positive cells on mesangial.

\section{Acknowledgment}

We express our gratitude the staff of Department of Biochemistry, Babol University School of Medicine for their assistance in collection of blood and liver tissue samples. We thank $\mathrm{Mr}$ Shikhzadeh for excellent technical assistance. This investigation was a collaborative work between the Cellular and Molecular Biology Research Center and the Faculty of Medicine. The financial aid has been provided by Research Council of University (No: 9031937). Also, this study was supported by the Research Council of Medicine faculty (p30-1-11582.).

\section{References}

1. Sheridan AM. Molecular Mechanisms Underlying Diabetic Nephropathy. Nephrology. 2006, 4 (8): 1-6.

2. Mauer SM, Steffes MW, et al. Structural-functional relationships in diabetic nephropathy. J Clin Invest. 1984; 74(4): 1143-55. PMID: 6480821

3. Kanwar YS, Wada J, Sun L, Xie P, Wallner EI, Chen S, et al. Diabetic nephropathy: mechanisms of renal disease progression. Exp Biol Med (Maywood). 233(1): 4-11.

4. Singh LP, Green K, Alexander M, Bassly S, Crook ED. Hexosamines and TGF-_1 use similar signaling pathways EUROPEAN JOURNAL August 16, 2007 OF MEDICAL RESEARCH 367 to mediate matrix protein synthesis in mesangial cells. Am J Physiol Renal Physiol, 2004, 286 (2): F409-F416. PMID: 14559714

5. Lee HB, Yu MR, Yang Y, Jiang Z, Ha H. Reactive oxygen species-regulated signaling pathways in diabetic nephro - pathy. J Am Soc Nephrol, 2003, 14 (8 Suppl 3):S241-S245. PMID: 12874439
6. Abdel-Wahab N, Wicks SJ, Mason RM, Chantry A. Decorin suppresses transforming growth factor- beta-induced expression of plasminogen activator inhibitor-1 in human mesangial cells through a mechanism that involves $\mathrm{Ca} 2+-$ dependent phosphorylation of Smad2 at serine- 240. Biochem J. 2002; 362 (Pt 3): 643-9. PMID: 11879191

7. Qujeq D, Pourghasm M, Joursaraei G, Feiyzi F, Farsi M, Faraji AS. Mononuclear derived from human umbilical cord normalize glycemia in alloxan-induced hyperglycemic rat. Cell Physiol Biochem. 2011; 28(2): 323-8. PMID: 21865740

8. Ruzicka K, Grskovic B, Pavlovic V, Qujeq D, Karimi A, Muller MM. Differentiation of human umbilical cord blood CD133+ stem cells towards myelo-monocytic lineage. Clin Chim Acta. 2004; 343(1-2): 85-92. PMID: 15115679

9. Grskovic B, Ruzicka K, Karimi A, Qujeq D, Müller MM. Cell cycle analysis of the CD133+ and CD133- cells isolated from Umbilical cord blood. Clin Chim Acta. 2004; 343(1-2): 173-8. PMID: 15115691

10. Dezfoolian A, Panahi M, Feizi F. Stereological evaluation of renal glomeruli in offspring of diabetic female rats. Yakhteh Med J. $2009 ; 11$ (1): 17-22.

11. Heidari Z, Sagheb H, Dezfoulian A, Barbarestani M, Noori H. A stereological analysis of renal glomeruli following chronic lead intoxication in rat during a continuous period of 8 weeks. Acta Med Iran. 2002; 40: 73-78.

12. Gundersen HJG, Bagger P, Bendtsen TF, Evans S.M, Korbo, L, Marcussen N, et al. The new stereological tools: Disector, fractionator nucleator and point sampled intercepts and their use in pathological research and diagnosis. APMIS. 1988; 96: 857-81. PMID: 3056461

13. Gilbert JS, Lang AL, Grant AR, Nijland MJ. Maternal nutrient restriction in sheep: hypertension and decreased nephron number in offspring at 9 months of age. J Physiol. 2005; 565(Pt 1): 137-47. PMID: 15790663

14. Park JH, Park J. Hwang SH, Han H, Ha H. Delayed treatment with human umbilical cord blood-derived stem cells attenuates diabetic renal injury. Transplantat Proc. 2012, 44(4): 1123-6. PMID: 22564642

15. Abrass C, Spicer D, Berfield A, St. John P, Abrahamson D. Diabetes induces changes in glomerular development and lamsinin-B2 (s-laminin) expression. AM J Pathol. 1997; 11: 13114

16. Cosio Effects of high glucose concentrations on human mesangial cell proliferation. J Am Soc Nephrol. 1995; 5(8): 16009. PMID: 7756594 